\title{
The Moral Underpinnings of Technology
}

...The deeper problem is the overwhelming concentration of technical, financial and moral power in the hands of people who lack the training, experience, wisdom, trustworthiness, humility, and incentives to exercise that power responsibly.

\section{Stephens [1]}

As we've stressed throughout, Ethics is one of the prime features of Wicked Messes. Indeed, it's one of the most critical elements of Pragmatist Inquiry Systems. It certainly is one of the most important components of all crises, indeed of everything that humans do. As such, it plays a major role in Thinking the Unthinkable. For this reason alone, we need to address the Ethical and Moral underpinnings of technology.

First of all, it's often asked, "How does Ethics play a part in Natural Disasters that by definition are not caused by humans?" The short answer is that it is we not Mother Nature who make the crucial decisions where and to what standards to build houses and other structures. As a result, all Disasters bear the indelible imprint of humans, and in this sense, are Human-Caused.

Utilitarianism and Deontology are two of the major schools and prominent theories of Ethics. In its original and classic formulation, the basic idea of Utilitarianism is "the greatest good for the greatest number." In the case of technology, something is "Ethical" if its benefits clearly exceed its disbenefits. The customary objection is, "What counts as benefits for which stakeholders, and why not for others?" And of course, who sets the "Ethical Threshold" as it were above which we say something is "Ethical or not"? That is, what the benefits are and how and why they exceed the disbenefits.

When it comes to technology, Utilitarianism fares extremely poor. If the proponents of a technology overly exaggerate and hype its benefits and downplay, if 
not ignore altogether, the costs or disbenefits, then Utilitarianism fails miserably as an adequate base for assessing the Ethical standing of a technology.

The basic idea of Deontology is that what is Ethical should not be based on consequences per se, but on whether a formal rule or principle can be "willed without contradiction as a general principle that is applicable to, and thereby Binding on, all of humanity at all times and places." According to the great German Philosopher Immanuel Kant, who is generally credited as the "Father" of Deontology, the classic case is that of lying. One cannot will lying as a general rule for it is inherently contradictory and thereby self-defeating. It would defeat our ever believing in anyone, and hence, The Truth! In the case of technology, one of the primary forms of Deontology is that "There should be as few restraints as possible placed upon innovation for it's absolutely essential to human progress; therefore, it must be protected at all costs." Again, the primary question is "essential to whom, and in all cases at all costs?"

Given the despicable behavior of today's tech companies, Kant must be rolling in his grave. We believe that he would be absolutely horrified by the actions of Facebook's CEO Mark Zuckerberg's misguided notion of "free expression," or whatever he calls it, to allow political ads that contain outright falsehoods and lies. The fact that there exists a deliberate mechanism to spread lies worldwide at the click of a mouse is nothing less than Kant's worst nightmare come to life. It's the height of Unethical behavior.

(It should be noted that YouTube fares no better when it comes to carrying political ads that contain outright lies. The point is that Unethical behavior is unfortunately not confined to one tech company and one alone.)

Such behavior has not gone without significant pushback. A total of 250 Facebook's employees have dissented in the strongest possible terms. In an open letter to Zuckerberg, they write:

Free speech and paid speech are not the same.

Misinformation affects us all. Our current policies on fact-checking people in political office, or those running for office, are a threat to what FB stands for. We strongly object to this policy as it stands. It doesn't protect voices, but instead allows politicians to weaponize our platform by targeting people who believe that content posted by political figures is trustworthy. ${ }^{2}$

In spite of the historic importance of Utilitarianism and Deontology, we want to take a different approach. A particular method known as Moral Foundations Theory or MFT is especially relevant for assessing the Moral and Ethical issues associated with technology.

\footnotetext{
${ }^{1}$ See Mitroff [2].

${ }^{2}$ Issac [3].
} 


\section{MFT}

MFT derives from the fields of evolutionary psychology and cultural anthropology. ${ }^{3}$ Compared to Utilitarianism and Deontology, MFT is based on how people actually experience Ethics and Morality. According to MFT, a person's Moral intuitions or instincts (feelings) not only come first, but take precedence over reason, and thus override it. In essence, because they are "too abstract," Utilitarianism and Deontology do not figure importantly in our everyday lives. Reason not only plays a secondary role, but basically justifies a person's initial moral instincts.

MFT employs a powerful metaphor to make its key point about the role of reason. The mind is likened to a large elephant with a tiny rider that attempts to control the huge beast. The "rider" is reason, and the "elephant" is all the nonrational emotions and instincts that govern human behavior. Over time, the rider does indeed gain control, but only by recognizing and making peace with the elephant.

MFT is based on two basic principles: Individualizing and Binding. The Individualizing Principles (care and fairness) serve to protect individuals from harm and injustice. The Binding Principles (loyalty, authority, and sanctity) help to establish groups that are loyal, cohesive, and cooperative. In this way, it also serves to protect them as well. To elaborate:

1. Care: Evolution endowed us with the ability to form deep attachments with one another. It allows us to be able to commiserate with the pain and distress of others. It's responsible for the fundamental virtues of kindness, gentleness, nurturance, sympathy, and compassion. It's the underlying basis of the principle "Do no harm!", which is of course an expression of a Deontological rule, but in a form to which one can relate more directly. To say the least, tech comes up short because care is not necessarily the basic, underlying principle that guides the behavior and goal of tech companies. It's certainly not seen as central to their basic mission.

2. Fairness: Survival necessitated that our ancestors not only had to learn to work well with their immediate families and clans, but also with others with whom they were not directly related. In brief, reciprocal altruism is the basis of the fundamental ideas of justice, rights, autonomy, and fairness. Tech also come up short here as well because if it embraced the principle of fairness then it would automatically include a much broader set of stakeholders such as a company's surrounding communities, the environment, and the most distant set of all, future generations.

3. Loyalty: Fidelity to a particular tribe was also necessary for survival. It's the basis of the principle of self-sacrifice for the group as a whole. It often finds expression in the desire "to be of service to a cause 'greater than oneself." If anything, tech is overly loyal to a narrow set of stakeholders, e.g., Venture Capitalists being among the primary who provide the basic operating capital to start a company.

${ }^{3}$ Graham et al. $[4,5]$. 
4. Authority: As primates, our ancestors had to learn to function and thereby survive in groups that contained hierarchies. The recognition of authority is necessary both for the ability to lead and to follow. It also plays a crucial role in the ability and willingness to honor traditions. The sad fact of the matter is that very few organizations give their members the power to challenge authority.

5. Sanctity: Avoiding contact with contaminants was and is crucial to survival. Evolution endowed our ancestors with the ability to be disgusted by and avoid what was found to be "dirty" and "unclean." Sanctity is the basis of traditions that emphasize the moral significance of maintaining the purity of the body. Purity takes on a particular role in an appalling number of organizations, namely they see themselves and their motives as "pure."

\section{The Ant-Vaccine Movement}

The Ant-Vaccine Movement provides a very interesting and relevant case. In 2017, using MFT, researchers surveyed 1007 American parents. ${ }^{4}$ “....Those most resistant to vaccines scored highest in two values: purity ('my body is a temple') and liberty ('I want to make my child's health care decisions')". "Deference to authority" also figured importantly in regard to whether one was willing to "adhere to the advice of experts like a pediatrician or the C.D.C."

\section{Proactive CM}

MFT serves as the underlying Ethical basis of Proactive CM organizations. They are built on the two Individualizing Principles of care and fairness. The three Binding Principles of Loyalty, Authority, and Sanctity further reinforce them. In fact, the validity of the Binding Principles depends on whether they support the Individualizing Principles.

\section{The Jungian Framework}

A special framework due to the pioneering work of the highly influential Swiss psychoanalyst Carl Jung is also extremely relevant for the topic at hand. ${ }^{5}$ It sheds needed additional light on the difficult issue of Ethics.

As a highly educated European early in the twentieth century, Jung was well versed in history, literature, philosophy, and psychology, to mention only a few of the many subjects with which he was familiar. No matter what the individual

\footnotetext{
${ }^{4}$ Hoffma [6].

${ }^{5}$ See Ian I. Mitroff, Lindan B. Hill, and Can M. Alpaslan, Op. Cit.
} 
subject that he examined, time and again he observed the same differences in perspectives with regard to how people approached the topic at hand.

At the one of the spectrum were those whom he termed Sensing Types. They not only focused on Details, Specifics, and the Present, but even more fundamental, Details, etc., were the underlying basis of Reality, and as a result, the only legitimate way of obtaining knowledge. One didn't know something for certain unless one had hard, precise, and verifiable facts about the specific matter at hand.

At the other end were Intuitive Types whose focus was on the Bigger Picture, Systems, and Wholes. They also were tuned to hypotheticals and the future. In other words, they didn't shy away from What-Ifs. Indeed, they embraced them for they were the key to The New.

For Jung, it was absolutely not the case where one type or perspective was "right" and the other was "wrong." Instead, they both "saw" and thereby "constructed" the world differently. Not only was it vital to understand each of them, but not to put either of them down. Far more than they were able to acknowledge, they not only needed one another to keep them honest, but to "round out" their perspectives, and thus give a "more complete picture of the world."

The differences between Sensing and Intuitive Types constituted one dimension of the Jungian Framework. The other, which was independent and thereby "orthogonal" to the first, concerned the differences between thinking and feeling types. The focus of thinking types was on impersonal modes of analysis such as economics, logic, mathematics, and hard science. In sharp contrast, the focus of feeling types was on people, i.e., the Human Impacts of ideas, plans, policies, in other words, Highly Personal Ways of Knowing. It's important to note that by feeling, Jung did not mean emotional, for each and every one of the psychological types could be extremely "emotional' in defending its view of Reality.

Putting the two dimensions together results in four very different personality types: (1) Sensing-Thinking or ST's for short; (2) Intuitive-Thinking or NT's as they are referred to; (3) Intuitive-Feeling or NF's; and (4) Sensing-Feeling or SF's ( $\mathrm{N}$ is used for intuition because the letter I is reserved for introverts. Conversely, $\mathrm{E}$ stands for extroverts, which is another key dimension of the Jungian Framework.). These four have very different and distinct approaches to technology, if not to the world and Reality in general.

ST's are focused exclusively on the known, verifiable properties and benefits of today's technologies. In effect, they are not only comfortable with reducing everything to exercises, but insist on it as a primary condition before knowledge can be said to result. In this way, ST is inherently evolutionary when it comes to technology. Not only does it extend the Present, but it doesn't threaten to disrupt it. At its best, it doesn't release a new technology until it is absolutely assured that it will perform as intended, and thereby cause no harm, or as little as possible. It's great weakness is its inability and unwillingness to envision how unknown, totally new and unexpected nefarious actors will exploit a technology's underlying weaknesses and inherent defects for their benefit. At its worst, not only is it unconcerned with unintended consequences, but is oblivious to them. 
In contrast, NT's are primarily concerned with groundbreaking, disruptive technologies that no one has ever imagined, let alone seen before. Thus, where ST's are Evolutionary, NT's are Revolutionary. Their great strength is that they are able to envision and bring about the future. Nonetheless, for all their ability to think and act systemically, their greatest weakness is also their disregard for how nefarious actors will take advantage of their marvelous creations. They are also unconcerned with the unintended consequences of their inventions and actions.

NF's are primarily concerned with the Human Impacts of technology, not only on the Present and society in general, but on future generations. This is their greatest strength. Their weakness is their general suspicion of technology period, not to mention their disdain for technologists because of their general lack of concern with people.

In our unremitting criticism of technology and especially the narrow thinking of far too many technologists, we are the first to admit that this book smacks heavily of NF. However, it's not devoid of the other perspectives as well.

SF's are primarily concerned with how technology affects them and their immediate friends and families. Unless something can be shown to have concrete and distinct social benefits to them personally, they are generally opposed to it.

It should be clear that these four have very different approaches to Ethics. Thus, ST's give their primary allegiance to Cost/Benefit Analysis. That is, a technology is warranted if the benefits clearly exceed the costs. In contrast, NT's also use Cost/Benefit Analysis but with a completely different twist. They run multiple Cost/Benefit Analyses to make sure they have not overlooked anything serious. Thus, where ST is partial to the first two IS's-Expert Consensus and Analytic Modeling - NT's are partial to Multiple Perspective IS's.

Given that Feeling overrides Thinking, NF's are in effect practitioners of MFT. Harm is extended to all of humanity. SF's practice MFT as well except they do it with a focus exclusively on their immediate families and friends.

Ideally, these four types need to work together to overcome their inherent weaknesses and limitations. Indeed, all of them are needed to give a systemic overview. Sadly, because of our work with countless groups over the years, the authors have seen repeatedly how difficult it is for the different types just to listen to one another, let alone work together. They literally speak and live in different realities. For this reason, where we can, we've exposed them to the Jungian Framework so that they can work more productively with one another.

The point is that our approaches to technology, the Unthinkable itself, are shaped by fundamental differences in psychology. These can either be an aid to how we think about and manage technology, or the greatest obstacle. In the words of Pogo, "We've met the enemy and he is us!" 


\section{Concluding Remarks}

We are also the first to acknowledge that MFT is an ideal (As we've used it, the Jungian Framework is as well.). Nonetheless, its "primary virtue" is that it gives an explicit scorecard against which to measure the CM behavior of every organization. Sadly, tech does not fare well with regard to each of the core principles.

\section{References}

1. Stephens B (2019) Facebook's unintended consequence. The New York Times, Saturday, 4 May 2019, p A19

2. Mitroff II (2018) Technology run amok: crisis management in the digital age. Palgrave Macmillan, New York

3. Issac M (2019) Dissent erupts at Facebook. The New York Times, Tuesday, 29 Oct 2019, p B1

4. Graham J, Nosek BA, Haidt J, Iyer R, Koleva S, Ditto PH (2011) Mapping the moral domain. J Pers Soc Psychol 101(2):366

5. Graham J, Haidt J, Koleva S, Motyl M, Iyer R, Wojcik SP, Ditto PH (2013) Moral foundations theory: the pragmatic validity of moral pluralism. In: Advances in experimental social psychology, vol 47. Academic Press, Cambridge, pp 55-130

6. Hoffma J (2019) How Ant-Vaccine sentiment took hold in US. The New York Times, Tuesday, 24 Sept 2019, p A21

Open Access This chapter is licensed under the terms of the Creative Commons Attribution 4.0 International License (http://creativecommons.org/licenses/by/4.0/), which permits use, sharing, adaptation, distribution and reproduction in any medium or format, as long as you give appropriate credit to the original author(s) and the source, provide a link to the Creative Commons license and indicate if changes were made.

The images or other third party material in this chapter are included in the chapter's Creative Commons license, unless indicated otherwise in a credit line to the material. If material is not included in the chapter's Creative Commons license and your intended use is not permitted by statutory regulation or exceeds the permitted use, you will need to obtain permission directly from the copyright holder.

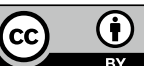

